Original Research

\title{
Research on Migration Law of Mn in Mudstone Floor in the Goaf under Coupling Conditions of Seepage and Stress
}

\author{
Deli Yang ${ }^{1}$, Junmeng Li1,*, Yanli Huang ${ }^{1}$, Tianqi Song ${ }^{2}$, Huadong Gao ${ }^{1}$, Ming Qiao ${ }^{1}$ \\ ${ }^{1}$ State Key Laboratory of Coal Resources and Safe Mining, School of Mines, China University of Mining \\ and Technology, Xuzhou, China \\ ${ }^{2}$ China Coal Energy Research Institute, Xi’an, China
}

Received: 30 August 2018

Accepted: 21 November 2018

\begin{abstract}
In recent years, as one of the green coal mining technologies, coal gangue filling and coal mining technology has been widely used. The coal gangue filling body in goaf may be in an acidic or alkaline mine water environment for a long time, and the rich heavy metal elements in coal gangue may pollute the groundwater environment. In order to predict the migration distance of heavy metal elements in the goaf floor more accurately, this paper first designed the coal gangue static immersion experiment. By using ICP, the concentration of heavy metal elements in the soaking solution was tested, and then the permeability stress sensitivity of mudstone was tested. Finally, based on the above experimental results, the numerical simulation model for migration of heavy metals in coal gangue under the condition of seepage-stress coupling was established by using COMSOL multiphysics, and the concentration distribution and seepage law of heavy metals in the mudstone floor of goaf were analyzed with Mn element as an example. The research results showed that the heavy metals with pollution risk in coal gangue soaking liquid were beryllium (Be) and manganese (Mn). The diffusion distance of heavy metal elements in all stress states was $9.537 \mathrm{~m}$ when using the traditional model. When calculating after combining with the modified model of permeability stress sensitivity analysis, when the stress states were $0 \mathrm{MPa}, 3 \mathrm{MPa}, 6 \mathrm{MPa}, 9 \mathrm{MPa}, 12 \mathrm{MPa}$ and $15 \mathrm{MPa}$, the diffusion distance of heavy metal elements was $9.326 \mathrm{~m}, 6.748 \mathrm{~m}, 5.9 \mathrm{~m}, 5.657 \mathrm{~m}, 5.558 \mathrm{~m}$ and $5.55 \mathrm{~m}$, respectively, and the reduction rate was $2.21 \%$, $29.24 \%, 38.14 \%, 40.68 \%, 41.72 \%$ and $41.80 \%$, respectively. The migration and concentration distribution of heavy metal elements were predicted more accurately, which provided a basis for predicting and evaluating the impact risk of coal gangue on groundwater in filling coal mining goaf.
\end{abstract}

Keywords: law of migration, Mn, seepage-stress coupling, COMSOL multiphysics, environment

*e-mail: lijunmeng1201@163.com 


\section{Introduction}

Solid filling technology for coal mining has become an important way of reducing the emissions of gangues, solving the problem of coal under buildings, railways or water, and also realizing the modern green mining, which has been popularized in almost 40 working faces in more than 10 mining areas [1-5]. With the large-scale filling of coal gangue as filling material into the goaf, the heavy metal elements in the filling body of coal gangue are in a state of secondary enrichment. Moreover, in the goaf there is substantial crack water and coal seam water from the roof strata. In this area, there is heavy stress and high temperature (in some mining areas the temperature even exceeds $40^{\circ}$ due to the influence of terrestrial heat) in the relatively enclosed environment. Due to being soaked in the mine water, coal gangues continuously release heavy metal elements and bring potential risk, as shown in the Fig. 1.

For a long time, much research has been conducted on the discipline of the temporal and spatial change of diffusion of contaminants released in the heaps of gangues on the ground and the gangue filling gob area under the mine. Zhang et al. [7] found that the heavy metal concentration dissolved from the coal gangues and the releasing rate are correlated not only to the $\mathrm{PH}$ value of leachate but to the content of heavy metal elements. Liu Guijian et al. [8] found through his research that there are many hazardous pollution components in coal gangue in which heavy metal ion pollution components are in the majority. Through the long-term immersion and showering of mine water, poisonous heavy metal components and inorganic salt are separated from the gangues. Baiwei Liu et al. [9-12], through the investigation of eco-hydrogeology, the leaching experiment using the solid column, field experiment and the analysis of underground water current, find that the gangues through long-term immersion will release diversified poisonous substances into the underground

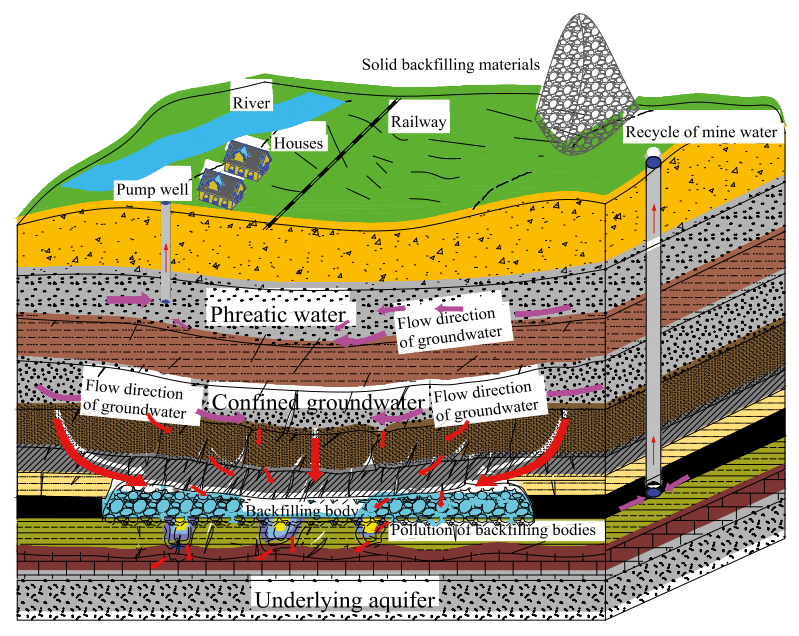

Fig. 1. Potential effects of coal gangue in goaf on groundwater environment [6-7]. water and change the primitive features of underground water current system. Wright et al. [13], after studying the underground water pollution caused by mine water, found that mine water with acidic $\mathrm{pH}$ value causes rising content of nickel, zinc, and manganese, thus destroying the ecosystem. Wang et al. [14], in the process of monitoring the filling gangue in the gob area, discover that in the whole leaching phrase, the $\mathrm{pH}$ value of mine water dissolution is positively related to the heavy metal concentration. Fanfani et al. [15], through analyzing the situation of underground water pollution in Coeurd Alene in northern Idaho in America, discovered that the emission of mine waste made the content of plumbum, zinc, and cadmium elements severely high, and the heaps of mine tailings have caused the dissolution the heavy metal elements. Han et al. [16] has studied and analyzed the influence caused by the sedimentation of the coal mine on the distribution feature and the temporal and spatial evolution of the migration of heavy metal and also analyzed the different concentrations and forms of the heavy metal in different situations of sedimentation. Tang and Li et al. [17], who have studied the distribution and migration of the six elements (including $\mathrm{As}, \mathrm{Cr}, \mathrm{Cu}, \mathrm{Mn}, \mathrm{Pb}$ and $\mathrm{Zn}$ ) in the gangues used as the filling stuff, find that $\mathrm{Mn}$ is in the dominant position. Moreover, the results according to the risk assessment code, and the individual pollution factors have shown that manganese has middle-ranked risk for the local environment, and other elements have lowlevel risk. In recent years, although many learners have studied the migration discipline of the heavy metal elements in gangues used as the filling stuff in the goaf, due to being irrespective of the mutual relation among the stress field, seepage field and the concentration field, their studies are not sufficient. Therefore, this paper uses the approach of combining laboratory experiments with numerical modeling in order to study the migration discipline of the $\mathrm{Mn}$ in the mudstone floor, which is under the coupling conditions of seepage and stress. Therefore, this research has its significant meaning for improving the theoretical system of the solid filling coal mining and the protection of underground water resources.

\section{Materials and Methods}

In order to predict the migration distance of heavy metal elements in the mudstone floor of the goaf more accurately, this paper first designed a static immersion test of coal gangue. By using ICP, the concentration of heavy metal elements in the soaking solution was tested, and then the permeability stress sensitivity of the mudstone was tested. Finally, based on the above experimental results, the numerical simulation model of heavy metal elements migration in coal gangue was established under the coupling of seepage and stress by using COMSOL multiphysics, and the concentration distribution and seepage law of heavy metal elements 


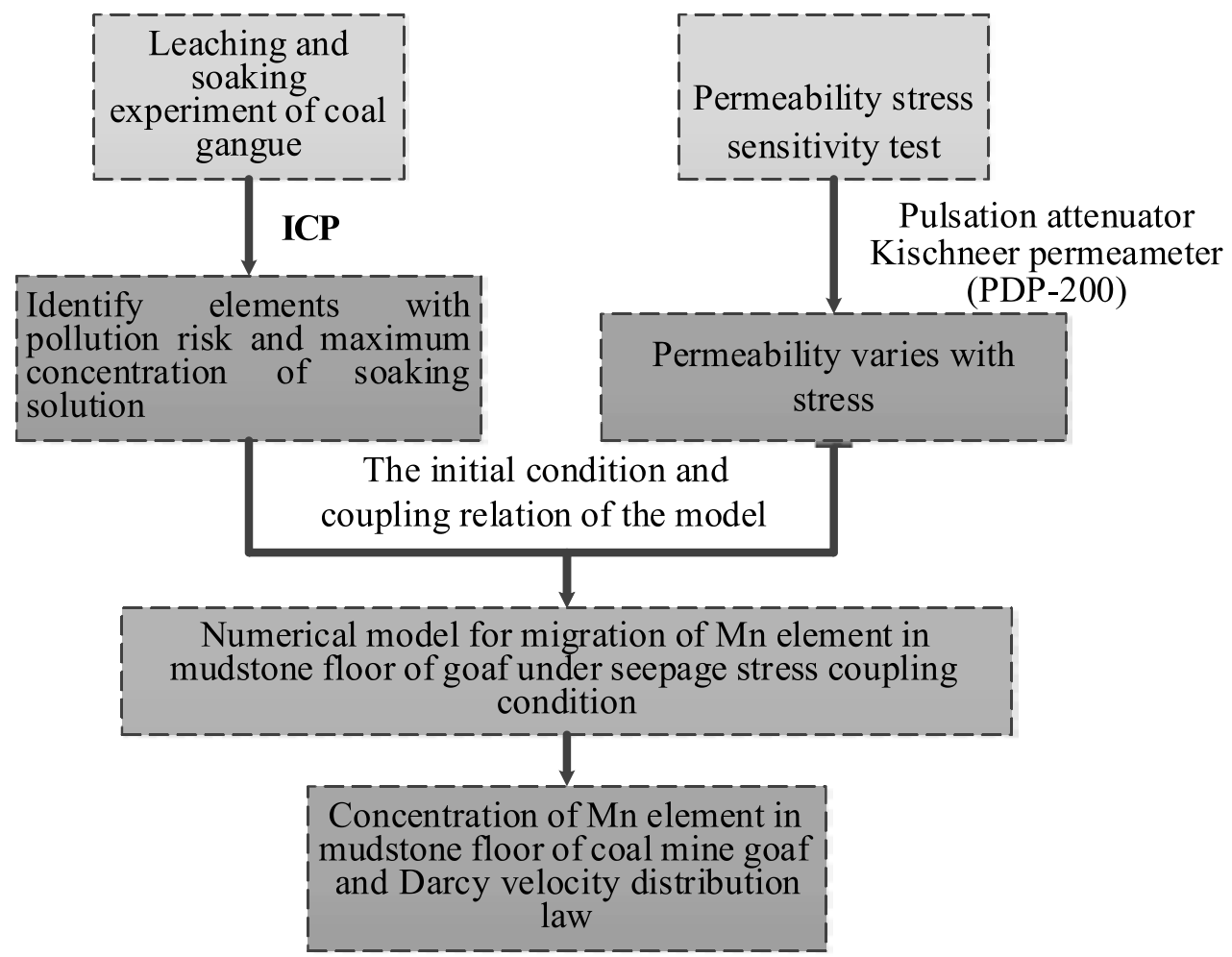

Fig. 2. Research ideas of paper.

in the mudstone floor of goaf with the Mn element as an example. The specific research idea is shown in Fig. 2.

\section{Experimental Materials and Sample Preparation}

\section{Static Soaking Experiment of Coal Gangue}

We smashed the coal gangues to pieces of less than $50 \mathrm{~mm}$ diameter using a crusher. As shown in Fig. 2, three representative coal gangues of 0-15 mm, $15-30 \mathrm{~mm}$ and $30-50 \mathrm{~mm}$ were selected as test samples. We also put the gangues with different diameters in place at $105^{\circ} \mathrm{C}$ in order to dry for 24 hours and then put the samples in a wide-mouth bottle. We used these gangues as representative samples.
We took out $1000 \mathrm{gA}(0-15 \mathrm{~mm}), \mathrm{B}(15-30 \mathrm{~mm})$, and $\mathrm{C}(30-50 \mathrm{~mm})$ as three kinds of single graded coal gangue samples and put them together in a largecapacity plastic bucket, and then put $10000 \mathrm{ml}$ mother liquids into the bucket in order to immerse these gangues. We took out the immersion liquid every 48 hours, and we put the liquid to be tested into a glass bottle and then sealed the bottles and labeled them. After gathering the liquid, we examined the liquids by inductively coupled plasma (ICP).

\section{Testing for Permeability Stress Sensitivity in Mudstone Floor}

In accordance with the requirements of the test, we used the driller for the sample rock to drill along the direction perpendicular to the bedding surface and a)

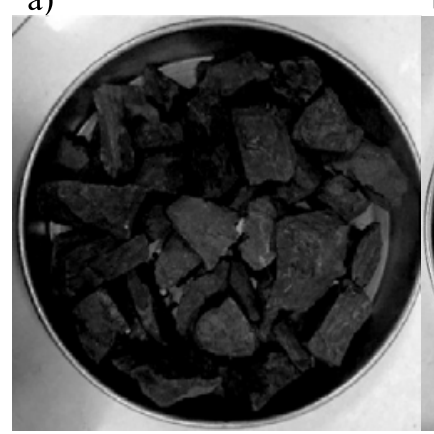

b)

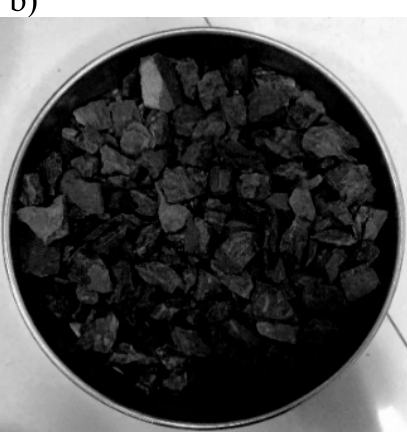

c)

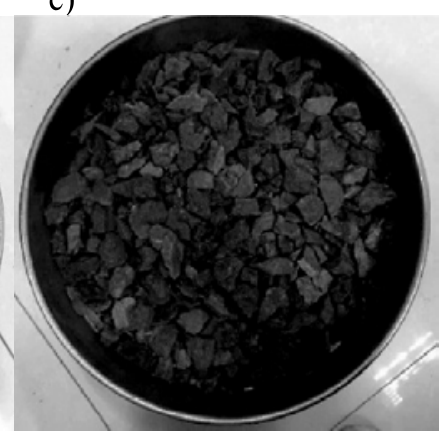

Fig. 3. Preparation of test samples: a) 30 50 mm, b) $15 \sim 30 \mathrm{~mm}$, c) $0 \sim 15 \mathrm{~mm}$. 


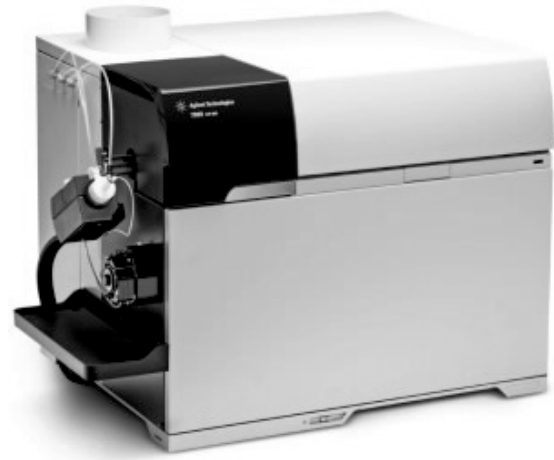

Fig. 4. LA-ICP-MS.

got out the cylinder with $25 \mathrm{~mm}$ diameter. After that we used the rock cutter to cut the rock core into the cylinder at $50 \mathrm{~mm}$ height and then used the face grinder to process the sample after cutting and made it into the standard specimen with the no more than $0.02 \mathrm{~mm}$ end surface evenness and no more than $0.05 \mathrm{~mm}$ degree of parallelism between upper and lower end faces.

\section{Test Instrument}

$$
L A-I C P-M S
$$

We conducted the quantitative analysis of the microelements, trace elements and super-trace elements in the liquid samples of soil, mineral, food, environment, biology and medicine, respectively by ICP-MS. This device has a low analytical detection limit, high precision, high accuracy and fast analytical speed and is able to conduct the isotopic analysis. We usually combined it with a laser ablation (LA) system and mainly applied this system to the analysis of microelements in geological samples. This paper used LA-ICP-MS to examine the concentration of heavy metal elements in gangue immersion liquid, as shown in Fig. 4.

\section{$X R D$}

XRD is widely used with coal, geology, the environment, material, chemical engineering, construction engineering, physical, metallurgy and machines. It is an influential device for testing the crystal texture and mineral content and is also the analytical study method of the relationships among the material microstructure and phase composition and macro performance. This paper used XRD to test the content of the background element of heavy metal elements in the gangues, as shown in Fig. 5.

\section{Pulsation Attenuator Kischneer Permeameter}

The pulsation attenuator Kischneer permeameter is an instrument using the non-stable method (pressure pulse attenuation method) to test the permeability of

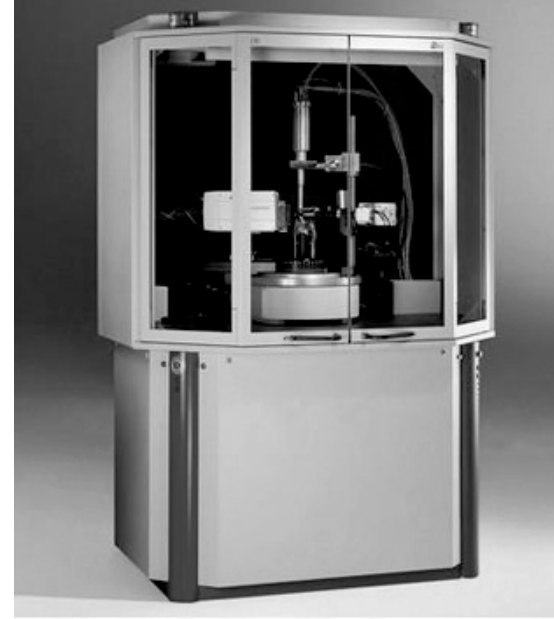

Fig. 5. X-ray diffractometer.

rock samples. Its duration is short and speed is fast. We use it to test the Kirschner permeability in the hypotonic and ultra-low permeable strata. The test for permeability stress sensitivity used hypotonic rock as a sample. For the purpose of reducing the experimental error caused by the test time and the slippage effect, this research used the pulsation attenuator Kischneer permeameter (PDP-200) to conduct the test, as shown in Fig. 6.

\section{Experimental Design}

First, the static immersion test of coal gangue was carried out, and the phase composition of coal gangue was tested by X-ray diffractometer to obtain the content of local elements. Since the mine water is mostly acidic, acid-deionized water with an initial $\mathrm{pH}$ of 5 was used as the mother liquor. The dissolution and release rule of heavy metal elements in the coal gangue under different particle sizes were studied by the method of coal gangue immersion test under normal room temperature conditions, providing a reference for the selection of initial values of numerical simulation of heavy metal elements migration in the floor rock stratum.

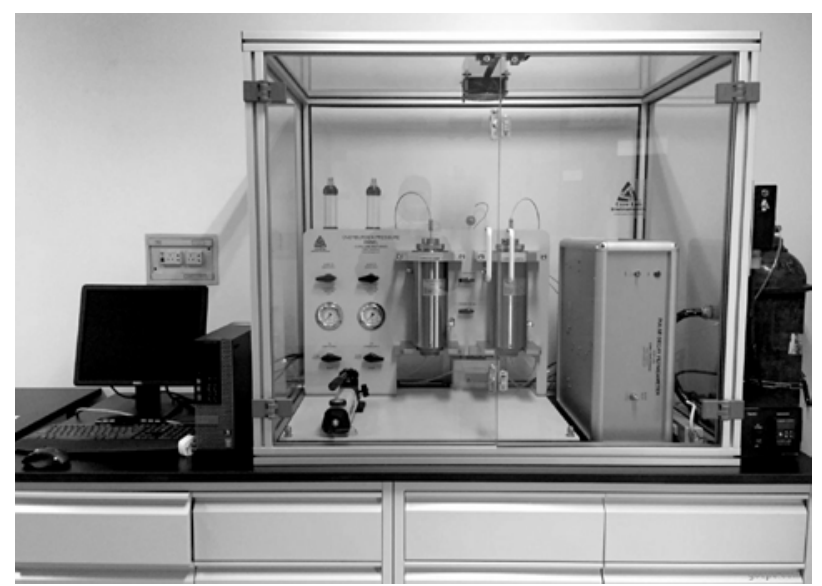

Fig. 6. Pulsation attenuator Kischneer permeameter (PDP-200). 


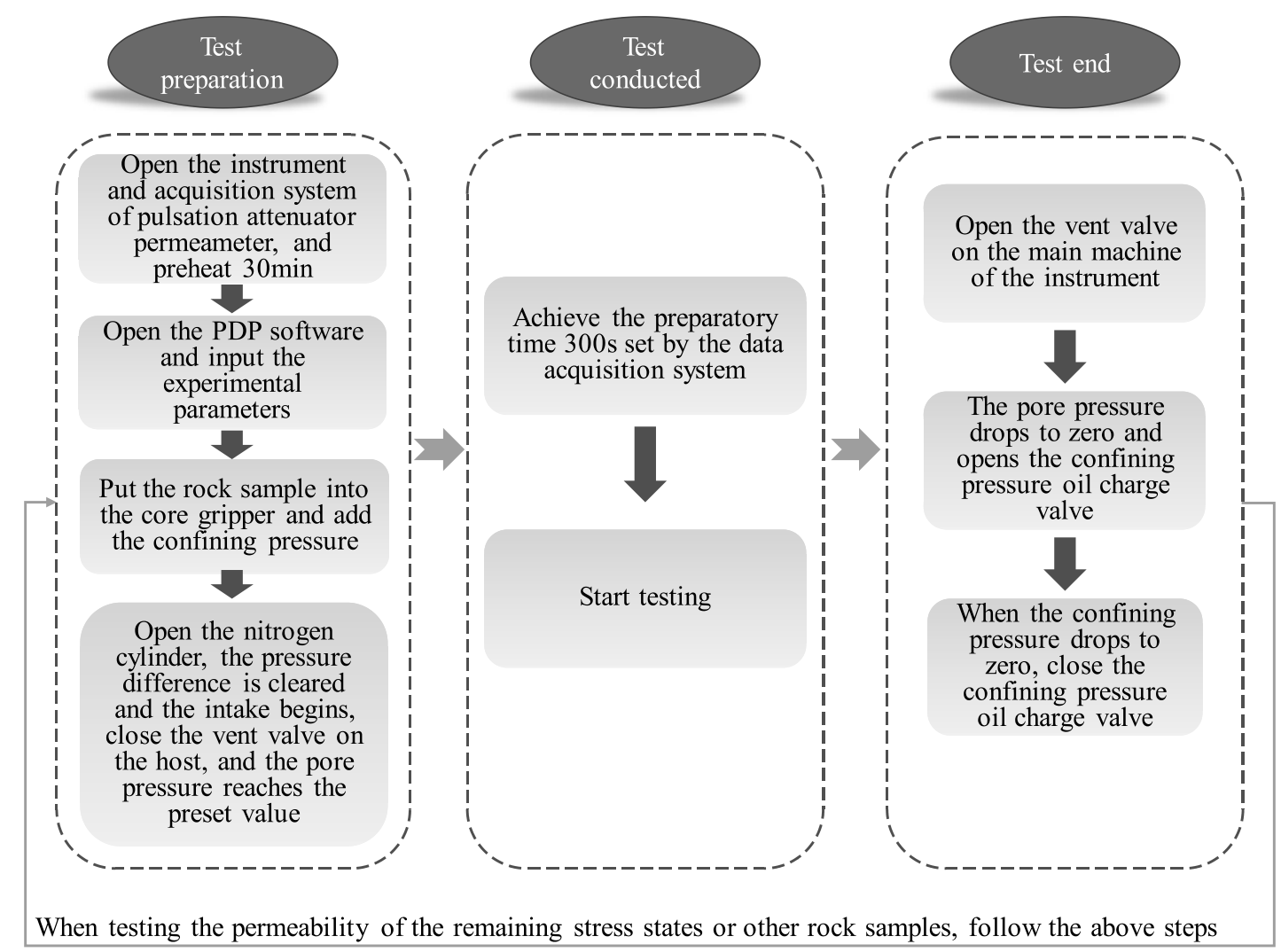

Fig. 7. Permeability test flow chart.

Then the permeability sensitivity test was carried out. The test tested the permeability of the mudstone floor specimens in the coal seam under different stress states. The test pressure of the specimens was $4 \mathrm{MPa}$. The confining pressure increased from low to high during the test. The effective stresses were $4 \mathrm{MPa}, 7$ $\mathrm{MPa}, 10 \mathrm{MPa}, 13 \mathrm{MPa}, 16 \mathrm{MPa}$, and $19 \mathrm{MPa}$, and the effective stresses were $0 \mathrm{MPa}, 3 \mathrm{MPa}, 6 \mathrm{MPa}, 9 \mathrm{MPa}$, $12 \mathrm{MPa}$, and $15 \mathrm{MPa}$, respectively.

After the preparation work before the permeability test, the permeability of the rock sample was tested. The specific test procedure is shown in the following figure:

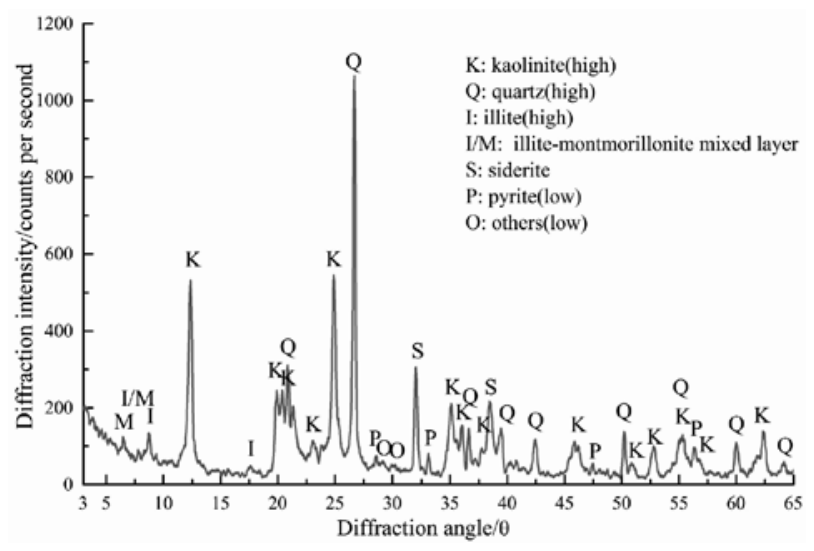

Fig. 8. XRD patterns of coal gangue [18].
Finally, based on the above experimental results, the numerical simulation model of heavy metal element migration in coal gangue under the condition of seepage stress coupling was established by using COMSOL Multiphysics, and the numerical simulation of the migration of heavy metals in the floor of the mudstone of the coal seam under 6 different stress states within 100 years was carried out with the Mn element as an example.

\section{Results and Discussion}

\section{Static Soaking Test of Coal Gangue \\ Determining the Content of Base Elements}

According to the $\mathrm{K}$ value method of standard GB5225--86, the content of the base elements in the coal gangue itself was quantitatively analyzed. The coal gangue in this paper was the same as the sample in the article [18], so the result of the experiment was quoted. The X- ray diffraction pattern of the coal gangue is shown in Fig. 8, and the result of the chemical composition test is shown in Table 1.

The composition of coal gangue is mainly $\mathrm{SiO}_{2}$ and $\mathrm{Al}_{2} \mathrm{O}_{3}$, accounting for $59.9 \%$ and $20.7 \%$, respectively. The heavy metals contained in chemical elements are mainly $\mathrm{Mn}, \mathrm{Be}, \mathrm{Cu}, \mathrm{Zn}, \mathrm{Ti}, \mathrm{Ba}, \mathrm{Pb}$ and other elements. 
Table 1. Content of elements or compounds in coal gangue [18].

\begin{tabular}{|c|c|c|c|}
\hline $\begin{array}{c}\text { Chemical } \\
\text { composition }\end{array}$ & Content/\% & $\begin{array}{c}\text { Chemical } \\
\text { composition }\end{array}$ & Content $/ \%$ \\
\hline $\mathrm{Na}_{2} \mathrm{O}$ & 0.65 & $\mathrm{~F}$ & $\leq 0.045$ \\
\hline $\mathrm{MgO}$ & 1.8 & $\mathrm{Ba}$ & 0.1 \\
\hline $\mathrm{Al}_{2} \mathrm{O}_{3}$ & 20.7 & $\mathrm{Mn}$ & 0.094 \\
\hline $\mathrm{SiO}_{2}$ & 59.9 & $\mathrm{Cu}$ & 0.0006 \\
\hline $\mathrm{K}_{2} \mathrm{O}$ & 2.4 & $\mathrm{~Pb}$ & $<0.0002$ \\
\hline $\mathrm{CaO}$ & 2 & $\mathrm{Zn}$ & 0.009 \\
\hline $\mathrm{Fe}_{2} \mathrm{O}_{3}$ & 6.7 & $\mathrm{Ti}$ & 0.5 \\
\hline $\mathrm{P}$ & 0.05 & $\mathrm{Be}$ & 0.011 \\
\hline $\mathrm{S}$ & 1.53 & & \\
\hline
\end{tabular}

\section{Dissolution and Release Rules of Heavy Metal Elements in Coal Gangue with Different Particle Sizes}

The concentration of heavy metal elements in the soaking liquid was detected by plasma emission spectrometer (ICP) according to the classification standard of groundwater quality in China. Under static immersion conditions, the dissolution and release rules of heavy metal elements in different sizes of coal gangue are shown in Fig. 9.

The figure shows:

(1) The dissolution and release of the above elements are roughly divided into two stages: rapid dissolution release period (0-8 days) and dissolution release equilibrium period (8-12 days). The dissolution release rate is fast during the fast dissolution release period, and the equilibrium period is slow. The release rate is gradually stabilized. In general, the release concentration increases with the immersion time, but the release rate gradually decreases as the immersion time increases.

(2) The dissolution rate of heavy metal elements is negatively correlated with the particle size. The smaller the particle size, the faster the release rate, and the performance is especially evident during the fast dissolution release period. This is because the smaller the particle size, the larger the specific surface area of the coal gangue in contact with water, and the higher the dissolution release rate of the metal element.

(3) According to the groundwater quality classification standard, when the particle size is 0-15 mm, $15-30 \mathrm{~mm}$, and $30-50 \mathrm{~mm}$, respectively, the dissolution concentration of Be element is finally stabilized at $0.014 \mathrm{mg} / \mathrm{L}, 0.022 \mathrm{mg} / \mathrm{L}$, and $0.018 \mathrm{mg} / \mathrm{L}$. The dissolved release concentration of $\mathrm{Mn}$ is finally stabilized at $2.18 \mathrm{mg} / \mathrm{L}, 1.816 \mathrm{mg} / \mathrm{L}$, and $1.048 \mathrm{mg} / \mathrm{L}$. The concentration of the $\mathrm{Mn}$ element is classified as groundwater quality class $\mathrm{V}$ according to the groundwater quality classification index. The main concentration exceeded the standard composition of beryllium (Be) and manganese (Mn). a)

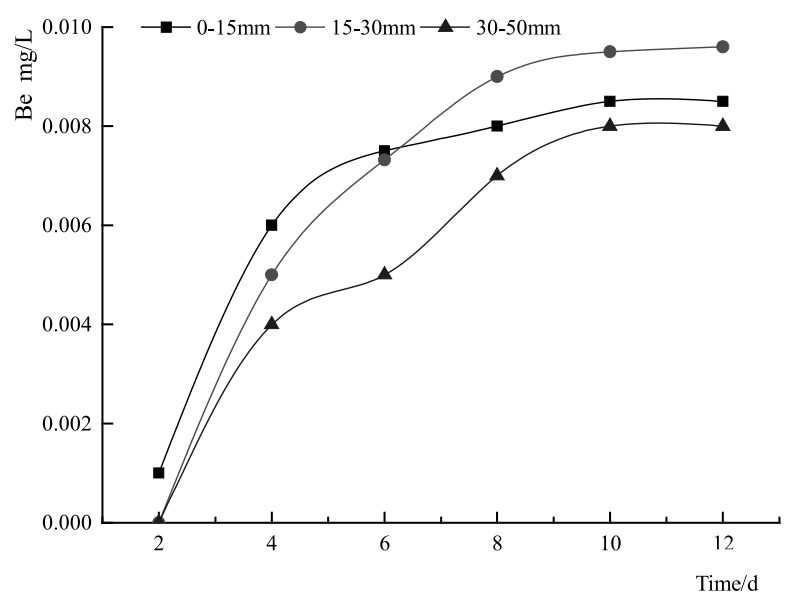

b)

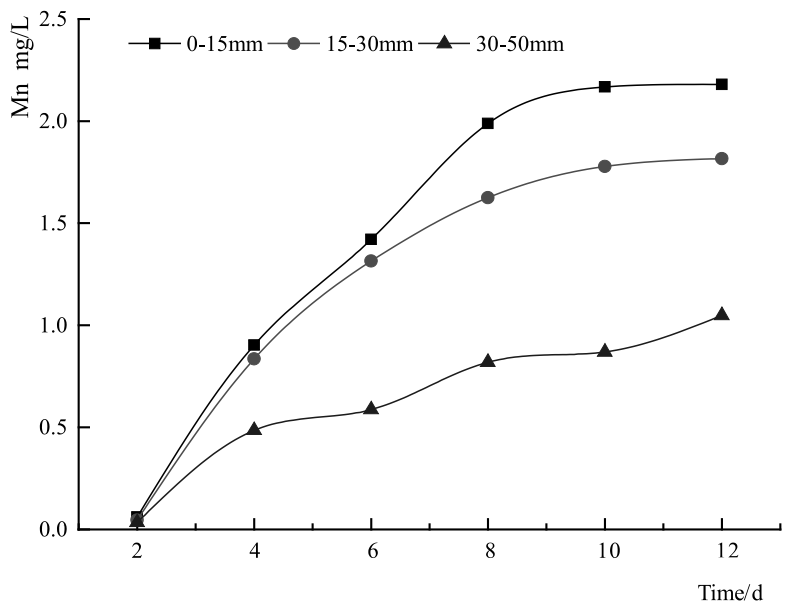

Fig. 9. Variation curves of heavy metal elements were analyzed by soaking coal gangue with different particle sizes: a) Be, b) Mn.

\section{Permeability Stress Sensitivity Test of Mudstone Floor}

\section{Relationship between Permeability and Effective Stress of Mudstone Floor}

Based on transient pulse test, the change fitting curve of permeability of common mudstone floor of coal seam with effective stress is shown in Fig. 10.

Fig. 10 shows:

(1) When the test pressure is kept constant at 4 $\mathrm{MPa}$, as the effective stress increases, the permeability of the rock sample decreases, and the permeability decreases with the increase of the effective stress. The permeability test data is fitted into an exponential function: $y=0.01686 \times \exp (-x / 2.6521)+0.00659$, the fitness $\mathrm{R}$ is 0.98436 .

(2) When the effective stress increases from $0 \mathrm{MPa}$ to $15 \mathrm{MPa}$, the permeability of mudstone is $0.02356 \mathrm{mD} \sim 0.00585 \mathrm{mD}$, the permeability decreases by $0.01771 \mathrm{mD}$, and the rate of change is $75 \%$. This is because the mudstone particles are larger and the 


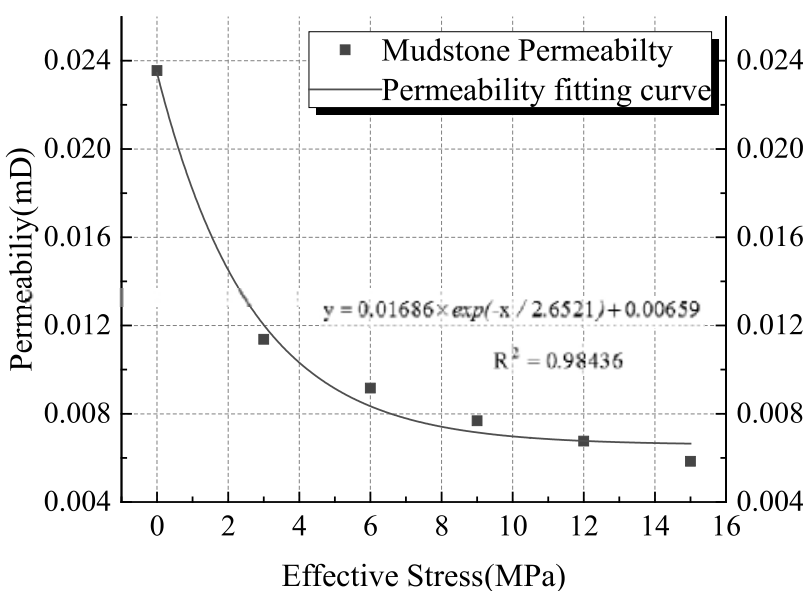

Fig. 10. The fitting curve of permeability with effective stress change.

sedimentation degree is lower and the porosity is higher. Therefore, the pores are continuously reduced during the pressurization process, resulting in a decrease in permeability, and the permeability changes significantly throughout the process.

\section{Characteristics of Permeability Sensitivity of Mudstone Floor Rock}

The description of the reservoir stress sensitivity by reference to the oil and gas industry standard describes the permeability sensitivity of the coal seam floor rock layer. The permeability damage sensitivity and the stress sensitivity coefficient are used to describe the permeability stress sensitivity.

The calculation formula for the permeability damage rate caused by the stress sensitivity of the floor rock layer is as follows:

$$
D=\frac{K_{0}-K^{\prime}}{K_{0}} \times 100 \%
$$

...where $\mathrm{D}$ is the value of the effective stress of the permeability during the continuous increase of the effective stress, $K_{0}$ is the initial permeability value $\mathrm{mD}$, and $K^{\prime}$ is the permeability value $\mathrm{mD}$ at a certain effective stress state.

According to the calculation formula of reservoir stress sensitivity coefficient commonly used in the oil and gas industry, the calculation formula of the stress sensitivity coefficient of the floor rock stratum is:

$$
\alpha_{K}=-\frac{1}{K_{0}} \frac{\partial K}{\partial P}
$$

...where $\alpha_{\mathrm{k}}$ is the stress sensitivity coefficient of the floor rock stratum, $K_{0}$ is the initial permeability, and $P$ is the effective stress.

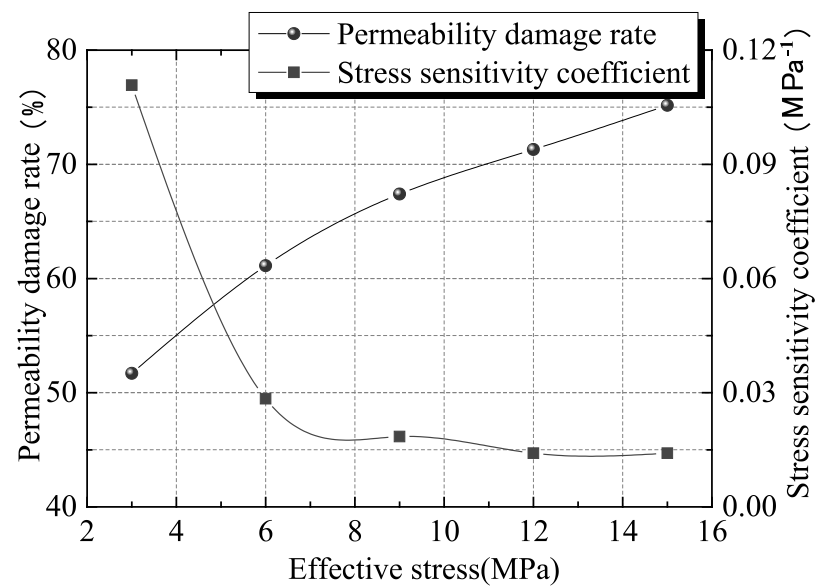

Fig. 11. Relationship between permeability damage rate, stress sensitivity coefficient and effective stress.

According to formulas 1 and 2, the calculation results of the permeability damage rate and the stress sensitivity coefficient of the mudstone floor rock formation are shown in Fig. 11.

Fig. 11 shows:

(1) The stress sensitivity coefficient of mudstone specimens varies greatly between $3 \mathrm{MPa}$ and $12 \mathrm{MPa}$, and gradually stabilizes after reaching $12 \mathrm{MPa}$. This is due to the large porosity of the mudstone. The pore closure is slower during the increase of the effective stress. After reaching $12 \mathrm{MPa}$, the pore is almost completely closed, and the effect of further pressure on permeability sensitivity is not significant. It is shown that porosity is one of the most important factors affecting the permeability sensitivity of the floor rock.

(2) Under different effective stresses, that is coal seam floor in different stress states (the state of the buried depth), the permeability sensitivity coefficient decreases with the increase of the effective stress, which is due to the stress of the coal seam floor rock layer. The pores are compacted and accompanied by plastic deformation, resulting in a significant decrease in permeability. Under high geo-stress conditions, the permeability sensitivity of the coal stratum floor will be weakened.

\section{Numerical Modeling of the Migration Discipline of Mn Element in Mudstone Floor}

Based on the test of the dissolution and release of heavy metal elements in previous coal gangues and the permeability stress sensitivity in the mudstone floor in goaf, we took the relationship between mudstone floor and permeability to study the migration law of heavy metal elements in coal gangues before and after considering the stress-seepage coupling. This section took the coal stratum as the porous medium and took advantage of COMSOL multiphysics numerical model software to carry out the numerical simulation calculation for the migration of the heavy metal elements 
Table 2. Setting of boundary conditions.

\begin{tabular}{|c|c|c|c|}
\hline Physical field & Boundary condition type & Governing equation & Boundary number or region \\
\hline \multirow{3}{*}{ Solid mechanics (solid) } & Fixed constraint & $\mathrm{u}=0$ & 2 \\
\cline { 2 - 4 } & Roller support & $\mathrm{n} \cdot \mathrm{u}=0$ & $1,3,6,8,11,12$ \\
\cline { 2 - 4 } & Boundary load & $\mathrm{S} \cdot \mathrm{n}=\mathrm{F}_{\mathrm{A}}$ & $5,7,10$ \\
\hline \multirow{3}{*}{\begin{tabular}{c} 
Richards equation (dl) \\
\multirow{3}{*}{$\begin{array}{c}\text { Transmission of porous material } \\
\text { (tds) }\end{array}$}
\end{tabular}} & Mass flux & $-\mathrm{n} \cdot \rho \mathrm{u}=\mathrm{N}_{0}$ & $2,6,7,8$ \\
\cline { 2 - 4 } & No flow & $-\mathrm{n} \cdot \rho \mathrm{u}=0$ & $1,3,5,10,11,12$ \\
\cline { 2 - 4 } & Water head & $\mathrm{P}=\rho \mathrm{g}\left(\mathrm{H}_{0}-\mathrm{D}\right)$ & $6,7,8$ \\
\cline { 2 - 4 } & No flux & $-\mathrm{n} \cdot \mathrm{N}_{\mathrm{i}}=0$ & $1,3,5,10,11,12$ \\
\hline \multirow{2}{*}{$\begin{array}{c}\text { Inflow } \\
\mathrm{c}_{\mathrm{i}}=\mathrm{c}_{0, \mathrm{j}}\end{array}$} & $6,7,8$ \\
\hline
\end{tabular}

in mudstone floor. According to the index of the classification of groundwater quality, BE and $\mathrm{Mn}$ was the overconcentration group in the gangue immersion liquid and due to the little influence of the type of the heavy metal elements on the migration, this research took the elements as the experimental target and studied the migration of Mn elements in mudstone floor in five stress situations.

\section{Model and Boundary Condition}

We constructed the two-dimensional model based on the concrete situation of the filling mining face and set up the geometrical parameters as follows: the length of working face was $100 \mathrm{~m}$, the width of section coal pillar was $30 \mathrm{~m}$ and the thickness of coal stratum we worked on was $3 \mathrm{~m}$ and the thickness of floor was $37 \mathrm{~m}$. We used the mapping for the mesh generation of the geometrical model. Grid cell size was $0.5 \times 0.5 \mathrm{~m}$. The standardizing of grid size was the superfine size in fluid dynamics. The concrete geometrical model is shown in Fig. 12. When establishing the numerical model, the fitting formula of permeability and effective stress was added to boundary conditions. Permeability in the model was adjusted at different positions according to the change of stress in order to achieve the purpose of stress-seepage coupling.
The concentration distribution and migration distance of heavy metal elements can be predicted more precisely by taking permeability stress sensitivity into account in numerical simulation. As a result which, the risk of groundwater pollution by heavy metal ions in solid filling coal mining can be evaluated more accurately, and make reasonable prevention and control measures based on the assessment results so as to protect the groundwater environment more scientifically.

According to the test result of the discipline of dissolution and release of heavy metal elements in gangues, having taken the filling stuff with its diameter between $15-30 \mathrm{~mm}$ into consideration, we took the stable concentration of the Mn element with the diameter between $15-30 \mathrm{~mm}$ as the primitive value of numerical model and took the primitive value of the setting of inflow boundary condition as $3.2 \mathrm{e}-5 \mathrm{~mol} / \mathrm{m}^{3}$. The numbers of all boundaries of this geometrical model are shown in Fig. 8. The boundary conditions and controlling equations are shown in Table 2.

\section{Simulation of Concrete Program}

In order to conduct the researches of the different migration disciplines of heavy metal elements in

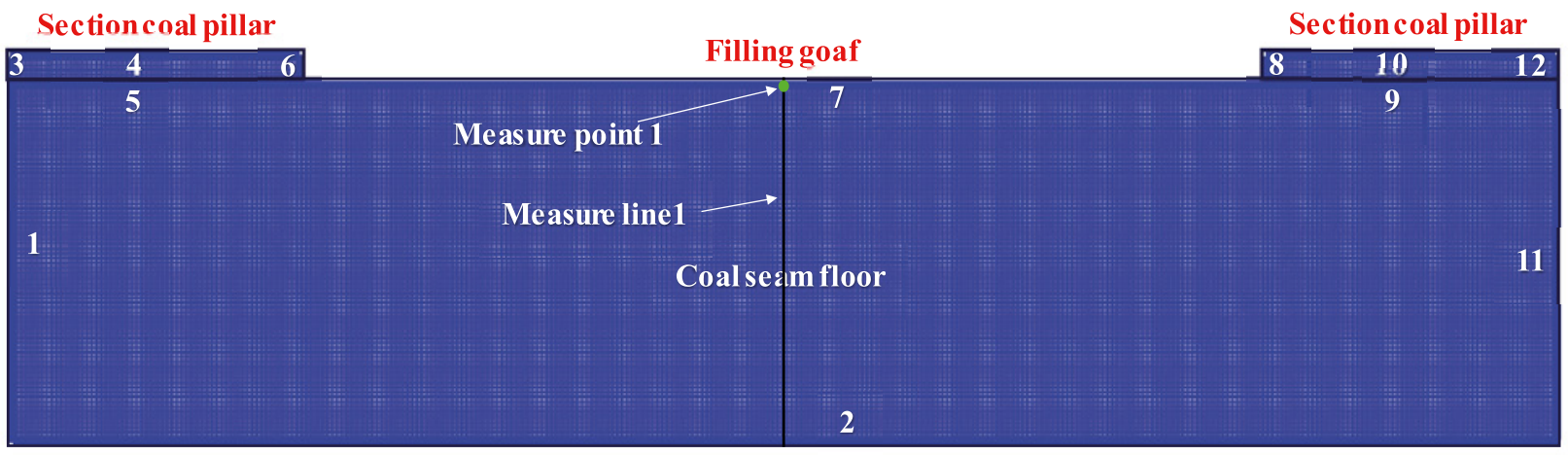

Fig. 12. Geometrical model of numerical simulation. 
Table 3. Numerical simulation calculation scheme.

\begin{tabular}{|c|c|c|}
\hline Number & $\begin{array}{l}\text { Boundary } \\
\text { load/MPa }\end{array}$ & Coupling relationship \\
\hline Scheme 1 & No stress field & $\begin{array}{l}\text { Non coupling relationship } k \text { is a } \\
\text { constant }\end{array}$ \\
\hline Scheme 2 & 0 & \multirow{6}{*}{$\begin{array}{c}k=0.01686 \times \exp (-s / 2.6521) \\
+0.00659\end{array}$} \\
\hline Scheme 3 & 3 & \\
\hline Scheme 4 & 5 & \\
\hline Scheme 5 & 8 & \\
\hline Scheme 6 & 12 & \\
\hline Scheme 7 & 15 & \\
\hline
\end{tabular}

gangues before and after the coupling of stress and seepage, we utilized the COMSOL Multiphysics numerical model software to conduct the simulation of calculating the value of the migration of the heavy metal elements in six different stress conditions within 100 years. The concrete numerical model program is shown in Table 3.

\section{Distribution Law of the Concentration Field}

According to the results of the test of solubility and release of heavy metal elements in gangues, Be and $\mathrm{Mn}$ were the main the heavy metal elements exceeding the standard. Due to the consistency of the migration law of different heavy metal ions in the floor strata, this

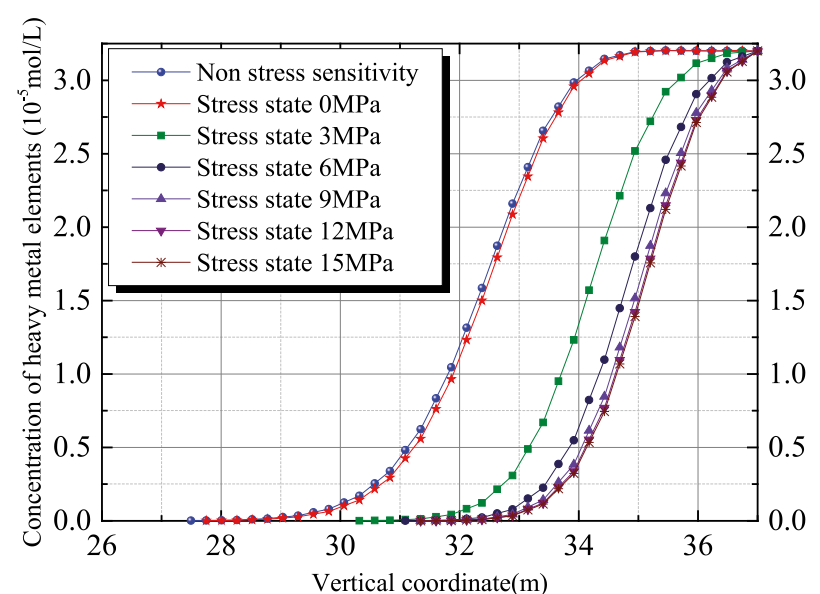

Fig. 14. Concentration distribution curve graph of Mn elements in mudstone floor before and after considering stress sensitivity.

paper selected one of these heavy metal element Mn ions to conduct the research. We utilized the COMSOL multiphysics numerical model software to conduct the numerical simulation calculation for the migration of the heavy metal elements in six different stress conditions within 100 years and gained seven programs of the concentration distribution pattern of Mn element in the 100th year, as shown in Fig. 10. In order to analyze the concentration distribution discipline of the direction of depth of rock floor, we placed the measuring line one. The concentration of the measuring line one exactly when the simulation was over is shown in Fig. 13.

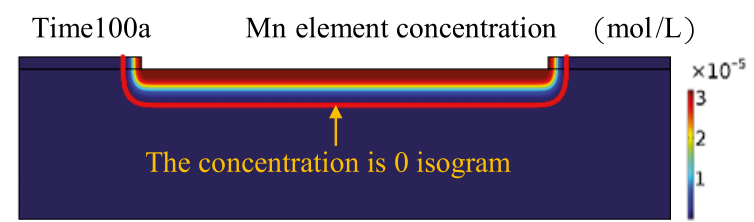

a) Scheme 1

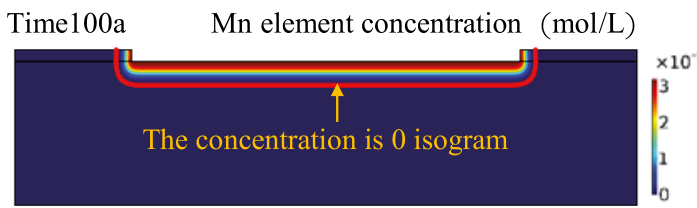

c)Scheme 3

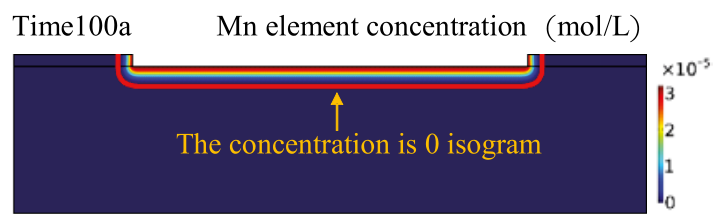

e) Scheme 5

Time100a Mn element concentration $(\mathrm{mol} / \mathrm{L})$

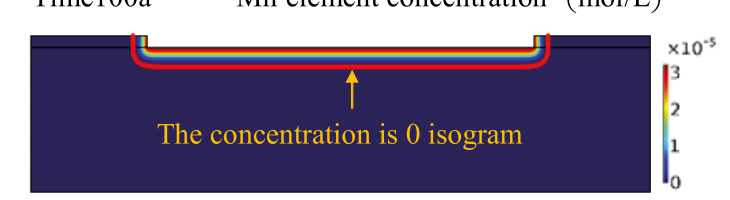

g) Scheme 7

f) Scheme 6

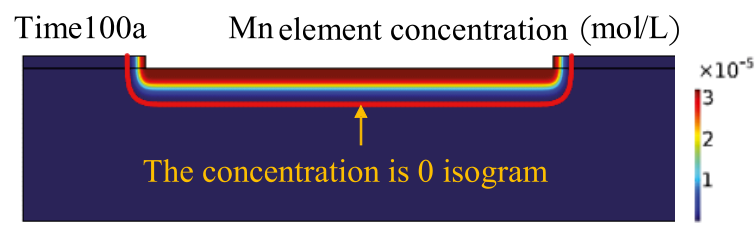

b) Scheme 2

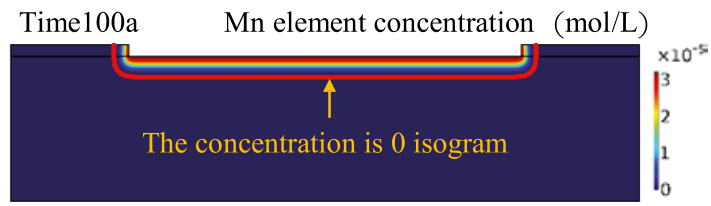

d) Scheme 4

Time100a Mn element concentration (mol/L)

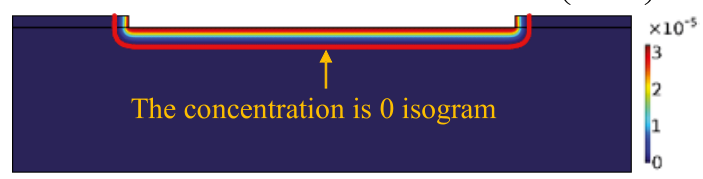

Fig. 13. Concentration distribution cloud map of Mn elements in mudstone floor before and after considering stress sensitivity. 
As shown in Figs. 13-14:

When calculating before and after considering permeability sensitivity, under the different stress states, the heavy metal elements in the depth direction of the floor keep decreasing with the increase of the depth, and the concentration is highest at the boundary between goaf and floor rock stratum, close to the initial concentration. This is due to the non-sifting filtration of the Mn element during the migration of the floor rock stratum with the surface of the mudstone. Through Brown diffusion, Mn elements diffuse from the flow to the surface of mudstone particles, leading to a gradual decrease in the concentration of Mn elements during migration. However, after taking into account the permeability stress sensitivity, the concentration distribution law of $\mathrm{Mn}$ elements in floor rock stratum changes at the end of the numerical calculation, and the concentration of $\mathrm{Mn}$ elements decreases with the increase of stress stage at the same position. When the permeability stress sensitivity model is used, the decrease rate of $\mathrm{Mn}$ element concentration is negatively related to the stress state. The greater the stress, the smaller the decrease, because the permeability stress sensitivity of the mudstone floor decreases with the increase of stress state. This phenomenon can be illustrated by the previous data from the permeability stress sensitivity test.

The diffusion range of heavy metal elements is determined according to the distance from the isoline with the concentration of 0 in concentration cloud map to the bottom of goaf, and the diffusion range of heavy metal elements in different stress states is obtained, as shown in Fig. 15.

Fig. 15 shows:

The traditional model is used to calculate without considering the permeability stress sensitivity. When the simulation reaches $100 \mathrm{a}$, the diffusion distance of heavy metal elements along the bottom depth is $9.537 \mathrm{~m}$. When the modified model is used to calculate and the stress states are $0 \mathrm{MPa}, 3 \mathrm{MPa}, 6 \mathrm{MPa}, 9 \mathrm{MPa}, 12 \mathrm{MPa}$, and

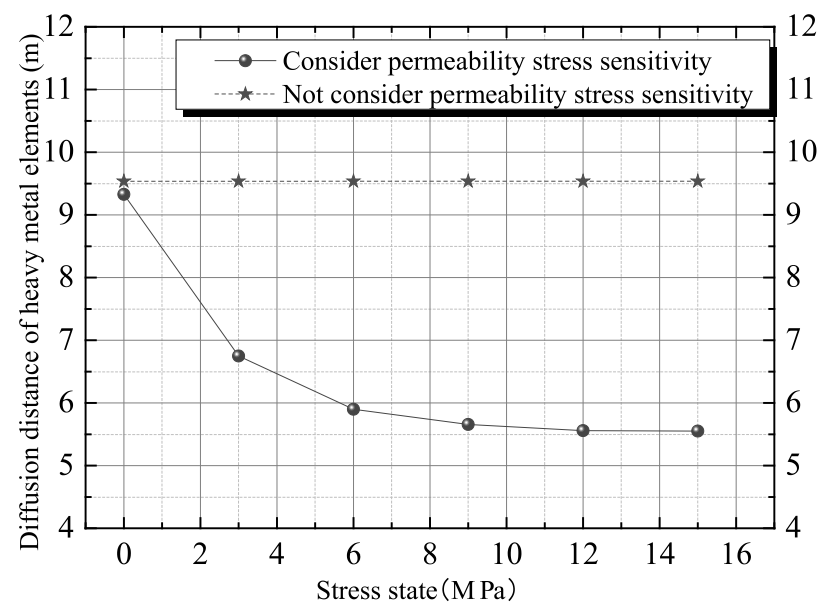

Fig. 15. Diffusion range of heavy metals under different stress states.
$15 \mathrm{MPa}$, the diffusion distance of heavy metal elements along the floor is $9.326 \mathrm{~m}, 6.748 \mathrm{~m}, 5.9 \mathrm{~m}, 5.657 \mathrm{~m}$, $5.558 \mathrm{~m}$ and $5.55 \mathrm{~m}$, respectively, and the change rates are $2.21 \%, 29.24 \%, 38.14 \%, 40.68 \%, 41.72 \%$, and $41.80 \%$, respectively. With the increase of stress, the diffusion distance decreases continuously, and the risk of groundwater pollution decreases continuously, and a non-linear decreasing trend is presented. This is due to the continuous closure of pore and fissure in the mudstone floor during the process of stress increase, resulting in the continuous decline of permeability and migration distance. When the stress is increased to a certain value, the pore channel and the crack are almost completely closed. If the stress is increased further, the permeability will change little, and the change range of migration distance will decrease.

\section{Distribution Law of Seepage Field}

By means of COMSOL multiphysics, the migration of heavy metal elements in the mudstone floor of coal seam under 6 different stress states within 100 years are numerically simulated and calculated, and the Darcy velocity distribution cloud map of Mn elements in seven schemes in 100 years is obtained, as shown in Fig. 16.

According to Fig. 16, it can be seen that:

(1) When the simulation time is $100 \mathrm{a}$, the seepage velocity in the mudstone floor is symmetrically distributed in the transverse direction, and decreases along the depth of the floor. This is due to the decrease of the pressure head in the mudstone floor with the increase of depth, which leads to decreasing Darcy seepage velocity along the depth direction, and the seepage velocity is mainly concentrated near the boundary between the goaf and the floor rock stratum.

(2) When the simulation time is $100 \mathrm{a}$, the Darcy seepage velocity is the largest at the bottom corner of the boundary of the goaf, the section coal pillar and the mudstone floor. This is due to the formation of Darcy seepage under the joint action of the vertical and horizontal pressure heads at the bottom corner of the goaf, so Darcy seepage velocity on the bottom corners on both sides of the goaf is larger than that in the middle.

(3) Before considering the sensitivity of permeability stress, the calculation results of Darcy seepage velocity are shown in Fig. 13a). After considering the permeability stress sensitivity, it can be clearly seen that the concentrated range of influence of the Darcy seepage velocity is scheme one $>$ scheme two $>$ scheme three $>$ scheme four $>$ scheme five $>$ scheme six $>$ scheme seven - all of which are reduced in varying degrees. This is because after taking into account the permeability stress sensitivity, in the process of increasing stress, the pore fissures of the mudstone floor are closed continuously, leading to the continuous decline of permeability and the continuous decrease of Darcy seepage velocity.

In order to further study the seepage law of the boundary between the goaf and the mudstone floor, 


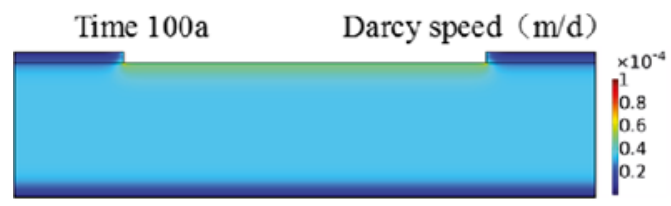

a) Scheme 1

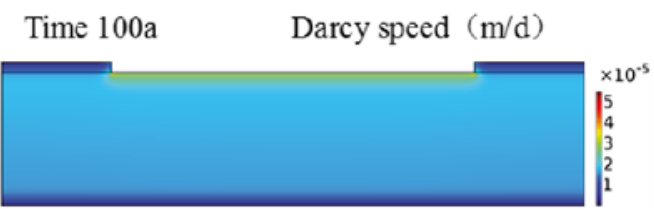

c) Scheme 3

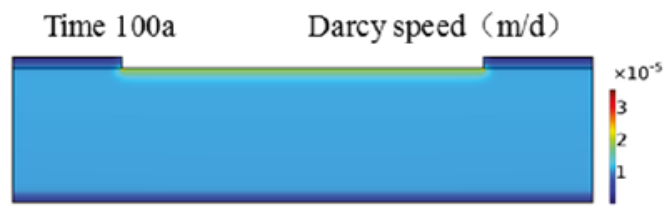

e) Scheme 5

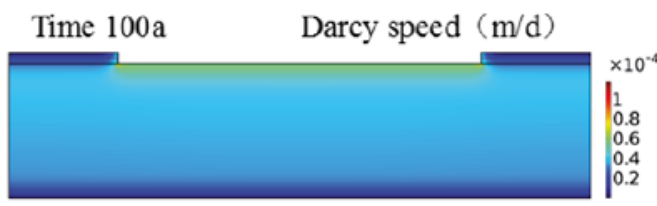

b) Scheme 2
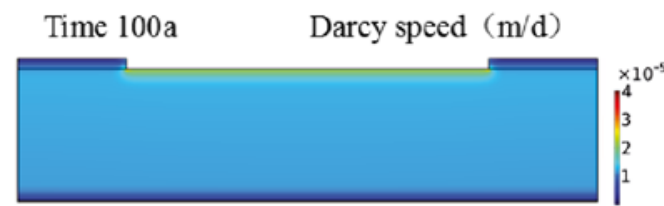

d) Scheme 4

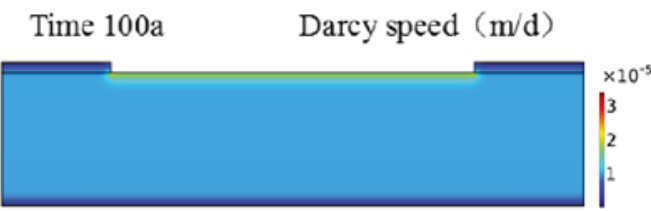

f) Scheme 6

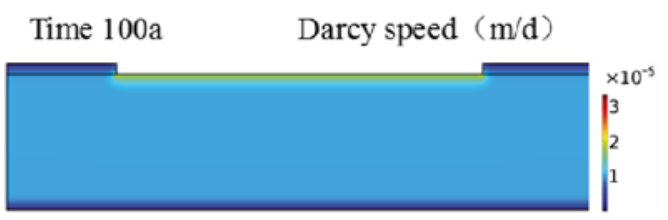

g) Scheme 7

Fig. 16. Darcy velocity distribution cloud map of Mn elements in mudstone floor before and after considering stress sensitivity.

the change rule of Darcy seepage velocity of measured point 1 in Fig. 9 with time is shown in Fig. 17.

Fig. 17 shows:

(1) The change rules of Darcy velocity at the boundary between the goaf and floor with time are roughly the same. All of them first increase to the maximum value and then gradually reduce to stability, which are roughly three stages respectively: the stage of rapid growth, slow down stage, and stable stage. This is because in the initial stage of seepage, Darcy seepage begins to appear in the mudstone floor under the effect

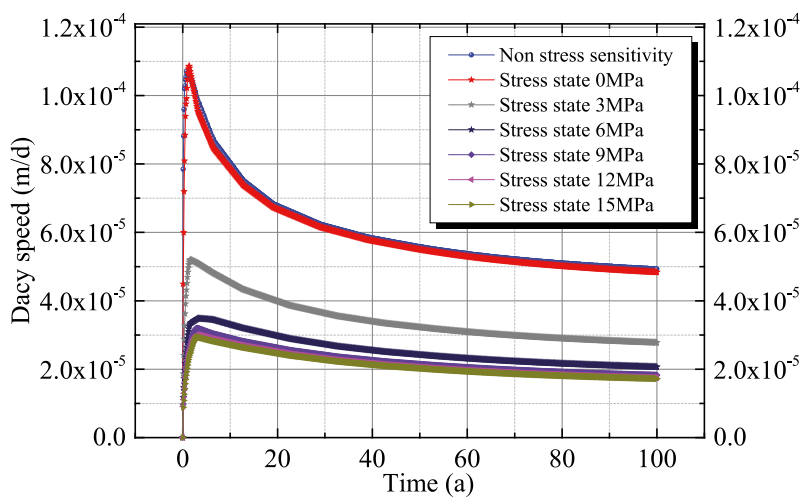

Fig. 17. Darcy velocity of Mn at measure point 1 in the mudstone floor. of pressure difference, and the Darcy seepage velocity increases from zero to the maximum at this time, however, with the increase of time, the water in the goaf continues to flow into the mudstone floor, leading to the continuous increase of water head of the measured point 1 , and the pressure difference decreases continuously. Finally, the seepage velocity of Darcy decreases and eventually becomes stable.

(2) The traditional model is used to calculate without considering the permeability stress sensitivity. When the simulation reaches $100 \mathrm{a}$, the steady value of Darcy seepage velocity is $5.69 \times 10-5 \mathrm{~m} / \mathrm{d}$. When the modified model is used to calculate and the stress states are $0 \mathrm{MPa}, 3 \mathrm{MPa}, 6 \mathrm{MPa}, 9 \mathrm{MPa}, 12 \mathrm{MPa}$, and $15 \mathrm{MPa}$, the stable values of Darcy seepage velocity are $5.59 \times 10-5 \mathrm{~m} / \mathrm{d}, 3.2 \times 10-5 \mathrm{~m} / \mathrm{d}$, $2.38 \times 10-5 \mathrm{~m} / \mathrm{d}, 2.11 \times 10-5 \mathrm{~m} / \mathrm{d}, 2.02 \times 10-5 \mathrm{~m} / \mathrm{d}$, and $1.99 \times 10-5 \mathrm{~m} / \mathrm{d}$ respectively, and the corresponding change rates are $1.75 \%, 43.76 \%, 58.17 \%, 62.92 \%$, $64.50 \%$, and $65.03 \%$ respectively. This is because after taking into account the permeability stress sensitivity, in the process of increasing stress the pore fissures of the mudstone floor are closed continuously, leading to the continuous decline of permeability and the continuous decrease of Darcy seepage velocity, and the higher the stress state, the greater the change of seepage velocity. 


\section{Conclusions}

In this paper, according to the migration law of Mn element in the floor under the seepage stress coupling condition, by the static immersion experiment, permeability stress sensitivity experiment and the numerical simulation of heavy metal elements migration in coal gangue under the condition of seepagestress coupling, the following main conclusions are obtained:

(1) According to the groundwater quality standards, $\mathrm{Mn}$ and $\mathrm{Be}$ are the elements with pollution risk, and their dissolution and release can be roughly divided into rapid dissolution release period and dissolution release equilibrium period. The dissolution release concentration of $\mathrm{Be}$ elements of sizes $0-15 \mathrm{~mm}$, $15-30 \mathrm{~mm}$ and $30-50 \mathrm{~mm}$ are stable at $0.014 \mathrm{mg} / \mathrm{L}$, $0.022 \mathrm{mg} / \mathrm{L}$ and $0.018 \mathrm{mg} / \mathrm{L}$, and the dissolution release concentration of Mn elements finally stabilizes at 2.18 $\mathrm{mg} / \mathrm{L}, 1.816 \mathrm{mg} / \mathrm{L}$ and $1.048 \mathrm{mg} / \mathrm{L}$.

(2) After considering the permeability stress sensitivity, with the increase of stress state, the concentration of $\mathrm{Mn}$ elements in the same position of the floor shows a decreasing trend, and the decrease of the concentration of $\mathrm{Mn}$ elements is negatively related to the stress state. The greater the stress state, the smaller the decrease of the stress state, which is because the permeability stress sensitivity of mudstone floor decreases with the increase of stress state.

(3) After considering the permeability stress sensitivity, the diffusion distance and Darcy seepage velocity decrease with the increase of stress, and the nonlinear decreasing trend is presented, which is due to the continuous closure of the pore fissures in the mudstone floor, which leads to the constant decrease of permeability.

\section{Acknowledgments}

Financial support for this work provided by the Fundamental Research Funds for the Central Universities (2017XKZD13) is gratefully acknowledged.

\section{Conflict of Interest}

The authors declare that the work described has not been published before; that it is not under consideration for publication anywhere else; that its publication has been approved by all co-authors; and that there are no conflicts of interest regarding the publication of this article.

\section{References}

1. HUANG Y.L., LI J.M., SONG T.Q., KONG G.Q., LI M. Analysis on filling ratio and shield supporting pressure for overburden movement control in coal mining with compacted backfilling [J]. Energies. 10 (1), 31, 2016.

2. HUANG Y.L., ZHANG J.X., YIN W., SUN Q. Analysis of overlying strata movement and behaviors in caving and solid backfilling mixed coal mining [J]. Energies. 10 (7), 1057, 2017.

3. ZHANG J.X., ZHANG Q., SPEARING A.J.S., MIAO X.X., GUO S., SUN Q. Green coal mining technique integrating mining-dressing-gas draining-backfillingmining. Int. J. Min. Sci. Technol. 27, 17, 2017.

4. JU F., HUANG P., GUO S., XIAO M., LAN L.X. A roof model and its application in solid backfilling mining. Int. J. Min. Sci. Technol. 27, 139, 2017.

5. CHEN Q.F., NIU W.J., LIU Y. Z., CHEN Q.L., LIU J.G., FAN Q.Y. Improvement of Knothe model and analysis on dynamic evolution law of strata movement in fill mining. [J]. China Univ. Min. Technol. 02, 250, 2017.

6. BAI H.B., MA D., CHEN ZHANQING. Mechanical behavior of groundwater seepage in karst collapse pillars [J]. Eng. Geol. 164, 101, 2013.

7. ZHANG H., OU Y.S., Release characteristics of heavy metals from coal gangue under simulation leaching conditions [J]. Energy Explor. Exploit. 32 (2), 413, 2014.

8. LIU G.J., YANG P.Y., PENG Z.C., JIANG W.U., WANG G.L. Study on leaching of potentially hazardous trace elements from coal-waste rocks [J]. Geol. J. China Univ. (04), 449, 2001.

9. LIU B. W., TANG Z.H., DONG S.G., WANG L.X., LIU D.W. Vegetation recovery and groundwater pollution control of coal gangue field in a semi-arid area for a field application [J]. Int. Biodeterior. Biodegrad. 128, 2018.

10. LI J.M., HUANG Y.L., SONG T.Q., YANG D.L., KONG G.Q. Study on the migration characteristics of $\mathrm{Cu}^{2+}$ ions of backfill gangue in subsided area [J]. Pol. J. Environ. Stud. 27 (1), 145, 2018.

11. DONG J.H., YU M., CHENG W., GE D.M., LI K.X. Safety of heavy metals pollution for wheat planted in reclaimed mining soil [J]. Trans. CSAE. (12), 280, 2010.

12. DONG J.H., BIAN Z.F., WANG H.F. Comparison of heavy metal contents between different reclaimed soils and the control soil $[\mathrm{J}]$. China Univ. Mining Technol. (04), 531, 2007.

13. WRIGHT I.A., PACIUSZKIEWICZ K., BELMER N. Increased Water Pollution after Closure of Australia's Longest Operating Underground Coal Mine: a 13-Month Study of Mine Drainage, Water Chemistry and River Ecology. Water Air Soil Pollut. 229 (3), 55, 2018.

14. WANG P., HU Z., WANG P. Attenuation of heavy metals by geosynthetics in the coal gangue-filled columns. Environ. Technol. 34 (20), 2893, 2013.

15. FANFANI L., ZUDDAS P., CHESSA A. Heavy metals speciation analysis as a tool for studying mine tailings weathering. J. Geochem. Explor. 58 (2-3), 241, 1997.

16. HAN F., ZHANG Y. Distribution Characteristic and Migration Pathways of Metals in Subsidence Zone in a Coal Mine, China [J]. Bull Environ. Contam. Toxicol. 98 (4), 539, 2017.

17. TANG Q., LI L., ZHANG S., ZHENG L., MIAO C. Characterization of heavy metals in coal gangue-reclaimed soils from a coal mining area. J. Geochem. Explor. 186, 1, 2018.

18. HUANG Y.L., LI J.M. SONG T.Q. ,SUN Q., KONG G.Q., WANG F.W. Microstructure of Coal Gangue and Precipitation of Heavy Metal Elements [J]. J. Spectrosc. 2017. 